\title{
HUBUNGAN KERAPATAN LAMUN DENGAN KEPADATAN BIVALVIA DI PESISIR PANTAI ORI KECAMATAN PULAU HARUKU
}

\author{
Asyik Nur Allifah $\mathrm{AF}^{1}$, Rosmawati $\mathrm{T}^{2}$ \\ ${ }^{1,2}$ Dosen Program Studi Pendidikan Biologi \\ E-mail:asyik.nur.allifah.af@gmail.com
}

\begin{abstract}
Abstrak: Penelitian ini dilaksanakan pada tanggal 21 Maret - 21 April 2017 di Pesisir Pantai Ori Kecamatan Pulau Haruku. Tipe penelitian yang digunakan yaitu penelitian kuantitatif dengan teknik pengambilan sampel dilakukan dengan purposive sampling. Untuk menghitung hubungan dari kerapatan lamun dan kepadatan bivalvia digunakan analisis korelasi sederhana dengan rumus pearson. Hasil penelitian menunjukkan bahwa jumlah total kerapatan lamun di Pesisir Pantai Ori Kecamatan Pulau Haruku pada kedua transek sebesar $367,5 \mathrm{ind} / \mathrm{m}^{2}$ yang termasuk dalam kategori rapat/lebat, sedangkan jumlah total kepadatan bivalvia pada kedua transek sebesar 6 ind $/ \mathrm{m}^{2}$. Hasil perhitungan uji korelasi diketahui nilai korelasi sebesar 0,347 yang berarti bahwa hubungan dari kerapatan lamun dan kepadatan bivalvia di Pesisir Pantai Ori kecamatan Pulau Haruku sangat lemah diperkuat dengan taraf signifikansi sebesar 0,653 lebih besar dari 0,05. Hal ini berarti bahwa tidak ada hubungan kerapatan lamun dengan kepadatan bivalvia di pesisir pantai Ori kecamatan pulau haruku.
\end{abstract}

\section{Kata Kunci: Kerapatan Lamun, Kepadatan Bivalvia}

Ekosistem pesisir merupakan ekosistem yang dinamis dan memiliki kekayaan habitat yang berlimpah baik di darat maupun di laut serta saling berinteraksi antara habitat tersebut. Lamun merupakan salah satu ekosistem sumber daya alam yang ada di laut dan banyak diminati oleh biota laut karena sangat bermanfaat. Lamun bisa dikatakan sebagai sumber kehidupan bagi biota laut. Hal ini di karenakan banyak hewan laut yang bisa mendapatkan makanan, tempat tinggal sekaligus tempat berkembang biak dari padang lamun. Azkab (1988), menjelaskan ekosistem lamun merupakan salah satu ekosistem dilaut dangkal yang paling produktif. Hal ini karena lamun memberikan tempat pelindungan dan tempat menempel berbagai hewan dan tumbuh-tumbuhan (alga) (Azkab, 1988). Salah satu jenis biota laut yang senang berada di padang lamun adalah bivalvia. Bivalvia merupakan salah satu kelas kedua terbesar dari vilum moluska setelah gastropoda yaitu sebanyak 31.000 spesies. Bivalvia termasuk kedalam hewan sesil yang tersebar di perairan pesisir seperti intertidal, dengan substrat lumpur bercampur pasir. Beberapa spesies bivalvia hidup pada substrat yang lebih keras lempung, kayu, atau batu, air tawar serta sedikit yang hidup di daratan (Resel \& Hunter, 1983).

Bivalvia adalah bagian dalam kelas moluska yang memiliki dua cangkang atau yang sering di sebut kerang. Padang lamun yang sering dijumpai di alam sering

BIOLOGI SEL (VOL 7 NO 1 EDISI JAN-JUL 2018 ISSN 2252-858X/E-ISSN 2541-1225) PAGE 81 
berasosiasi dengan flora dan fauna akuatik lainnya seperti alga, meiofauna, moluska, ekinidermata, krustacea dan berbagai ikan. Lamun dan bivalvia memiliki keterkaitan salah satunya memiliki karakteristik tipe substrat yang sama yang dijadikan sebagai habitat. Selain itu asosiasi lamun dan bivalvia mempunyai keterkaitan yang kuat dalam siklus makanan. Secara logika serasah pada lamun akan mengendap di dasar perairan yang kemudian di uraikan oleh mikroorganisme yang kemudian menjadi makanan bivalvia sedangkan hasil penguraian akan menjadi sumber makanan bagi larva, ikanikan kecil dan selanjutnya menjadi makanan bagi biota lain (Ghufron, 2011).

Pesisir pantai Ori Kecamatan Pulau Haruku merupakan wilayah pesisir pantai yang memiliki potensi sumber daya hayati yang beragam. Pesisir pantai Ori ini memiliki perairan laut cukup luas yang di dalamnya terdapat beberapa ekosistem secara umum, baik ekosistem mangrove, maupun lamun. Pesisir inimemiliki pantai yangberlumpur bercampur pasir. Komunitas padang lamun di pesisir pantai Ori memiliki sebaran yang cukup luas, sehingga beragam biota laut potensial berada di padang lamun terutama bivalvia. Meskipun lamun di pesisir pantai Ori memiliki potensi yang besar, namun informasi tentang potensi yang dimiliki khususnya kerapatan lamun dan kepatadan biota yang berasosiasi dengan lamun masih sangat minim dan tidak terinformasi dengan baik. Berdasarkan latar belakang diatas, maka penelitian tentang hubungan kerapatan lamun dan kepadatan bivalvia di pesisir pantai Ori Kecamatan Pulau Haruku, penting untuk dilakukan dengan tujuan untuk melihat sejauh mana hubungan kerapatan lamun terhadap kepadatan bivalvia di Pesisir Pantai Ori.Kecamatan Pulau Haruku

\section{METODE PENELITIAN}

Jenis penelitian yang di gunakan adalah kuantitatif yakni untuk mengetahui tentang Hubungan Kerapatan Lamun Dengan Kelimpahan Bivalvia Di Pesisir Pantai Ori Kecamatan Pulau Haruku. Populasi adalah keseluruhan objek yang di teliti. Yang menjadi populasi dalam penelitian ini adalah semua jenis bivalvia yangterdapat pada padang lamundi Pesisir Pantai Ori Kecamatan Pulau Haruku. Sampel merupakan bagian dari populasi (Mahi Hikmat, 2011). Dimana sampel yang akan diteliti adalah jenis bivalvia (kerang-kerangan) yang terdapatpada padang lamun di Pesisir Pantai Ori Kecamatan Pulau Haruku dengan teknik pengambilan sampel dilakukan dengan purposive sampling. Yaitu pengambilan sampel didasarkan pada kriteria tertentu (Anonim, 2014). Adapun tahapan pelaksanaan dalam penelitian ini adalah

1. Observasi lapangan dilakukan dengan cara melakukan pengamatan langsung

kondisi lapangan untuk menentukan stasiun pengambilan sampel. Kegiatan ini bertujuan untuk memperoleh gambaran awal tentang kondisi lapangan.

2. Penentuan stasiun pengamatan 
a) Dibuat garis transek pada titik yang telah ditetapkan sebagai pengambilan sampel dari pasang tertinggi sampai pada surut terendah.

b) Panjang pantai sekitar $800 \mathrm{~m}$, dengan panjang pantai yang ditumbuhi lamun sekitar $500 \mathrm{~m}$, lebar pantai $50 \mathrm{~m}$.

c) Ditarik secara vertikal garis transek sepanjang $50 \mathrm{~m}$ dari pasang tertinggi sampai pada surut terendah. Pada masing-masing garis transek diletakkan kuadran ukuran 1 x 1, jarak antar kuadran 2 meter.

3. Pengambilan sampel

a) Dihitung semua jenis bivalvia yang terdapat pada kuadran $1 \times 1$ meter, selanjutnya dicatat jumlahnya.

b) Masing-masing diambil 2 individu untuk spesies bivalvia yang ditemukan, disimpan dalam kantong plastik dan diberi label untuk diidentifikasi.

4. Pengukuran parameter lingkungan

a) Pengukuran parameter lingkungan yang dilakukan adalah pengukuran salinitas menggunakan refraktometer, pengukuran $\mathrm{pH}$ menggunakan $\mathrm{Ph}$ meter, suhu menggunakan termometer, pengukuran DO (oksigen terlarut) menggunakan DO meter. Selanjutnya alat yang digunakan dibersihkan menggunakan tissue.

b) Pengukuran salinitas, $\mathrm{pH}$, dan suhu langsung dilakukan dilapangan pada saat pengambilan sampel sedangkan pengukuran DO dilakukan di laboratorium.

Teknik analisis data yang digunakan adalah statistik deskriptif yaitu statistik yang digunakan menganalisis data dengan cara mengdeskripsikan data yang sudah terkumpul sebagaimana adanya tanpa bermaksud untuk membuat kesimpulan yang berlaku dalam umum atau generalisasi. Yang termaksud dalam teknik analisis data statistik deskriptif diantaranya seperti penyajian data dalam bentuk grafik, tabel, presentase, frekuensi, diagram dan lain-lain.

1. Kerapatan jenis lamun

Menurut Fachrul kondisi ekosistem padang lamun dapat dianalisis salah satunya dengan menghitung kerapatan jenis. Kerapatan jenis dilakukan untuk melihat perbandingan antara jumlah total individu (Ni) dengan unit area yang diukur (A). Kerapatan jenis lamun dapat dihitung berdasarkan persamaan (Putra, 2014):

Dimana:

$\mathrm{Ki}=$ kerapatan jenis ke- $\mathrm{i}$

$n i=$ Jumlah total dari jenis ke-i

$\mathrm{A}=$ Luas pengambilan sampel $\left(\mathrm{m}^{2}\right)$

$$
\mathrm{Ki}=\frac{\mathrm{m}_{i}}{A}
$$


2. Kepadatan bivalvia

Kepadatan merupakan jumlah individu persatuan luas (Brower dan Zar) dengan formulasi sebagai berikut:

$$
\mathrm{D}=\mathrm{Ni} / \mathrm{A}
$$

Dimana:

$\mathrm{D}=$ Kepadatan Bivalvia (ind $/ \mathrm{m}^{2}$ )

$\mathrm{Ni}=$ Jumlah Individu

$\mathrm{A}=$ Luas Petak Pengambilan Contoh $\left(\mathrm{m}^{2}\right)$

Untuk menghitung hubungan dari kerapatan lamun dan kepadatan bivalvia digunakan analisis korelasi sederhana dengan rumus pearson. Rumus yang dipergunakan untuk menghitung koefisien korelasi sederhana adalah sebagai berikut:

$$
r=\frac{n \sum x y-\left(\sum x\right)\left(\sum y\right)}{\sqrt{\left\{n \sum x^{2}-\left(\sum x\right)^{2}\right\}}\left\{n \sum y^{2}-\left(\sum y\right)^{2}\right\}}
$$

Dimana:

$\mathrm{n} \quad=$ banyaknya pasangan data jenis lamun dan jenis bivalvia

$\sum \mathrm{x} \quad=$ total jumlah dari jenis lamun

$\sum \mathrm{y} \quad=$ total jumlah dari jenis bivalvia

$\sum \mathrm{x}^{2} \quad=$ kuadrat dari total jumlah dari jenis lamun

$\sum \mathrm{y}^{2}=$ kuadrat dari total jumlah dari jenis bivalvia

$\sum x y=$ hasil perkalian dari total jumlah dari jenis lamun dan jenis bivalvia.

Dengan koefisien korelasi selalu berada di dalam range antara -1 sampai +1 . Kriteria hubungan (Nasir, M, 2009)

$\mathrm{r}=-1$, hubungan sangat kuat dan bersifat tidak searah

$\mathrm{r}=0$, tidak ada korelasi

$\mathrm{r}=0-0,5$ korelasi lemah

$\mathrm{r}=0,5-0,8$ korelasi sedang

$r=0,8-1$ korelasi kuat atau erat

$\mathrm{r}=1$ korelasi sempurna dan bersifat searah

\section{HASIL DAN PEMBAHASAN}

\section{Parameter Perairan}

Kondisi fisika-kimia perairan sangat mempengaruhi segala bentuk kehidupan organisme perairan. Karakteristik fisika-kimia akan memberikan pengaruh terhadap struktur komunitas biota yang hidup di dalamnya. Perubahan fisika-kimia perairan akan mengubah struktur komunitas biota perairan. Oleh sebab itu pengukuran parameter perairan sangat perlu untuk mengetahui struktur biota perairan. Hasil pengukuran kualitas perairan dapat dilihat pada tabel dibawah ini: 
Tabel 4.1 Hasil pengukuran kualitas perairan

\begin{tabular}{|l|l|c|c|c|}
\hline \multirow{2}{*}{ No } & \multicolumn{1}{|c|}{ Parameter } & \multicolumn{2}{|c|}{ Transek } & Baku Mutu \\
\cline { 3 - 4 } & & I & II & Biota \\
\hline 1. & Suhu $\left({ }^{\circ} \mathrm{C}\right)$ & $29^{\circ} \mathrm{C}$ & $30^{\circ} \mathrm{C}$ & $25-31^{\circ}$ \\
\hline 2. & Salinitas $(\%)$ & $28 \%$ o & $29 \%$ & $25-40 \%$ o \\
\hline 3. & pH & 7,3 & 7,4 & $7-8,5$ \\
\hline 4. & DO $(\mathrm{ppm})$ & 6,6 & 5,6 & $4,1-6,6$ \\
\hline
\end{tabular}

Sumber: Data primer 2017

a. Suhu

Hasil pengamatan menunjukkan suhu pada kedua transek pengamatan relatif tidak berbeda jauh yakni berkisar antara $29^{\circ} \mathrm{C}-30^{\circ} \mathrm{C}$, Rentang suhu pada lokasi penelitian dapat mendukung kehidupan dari biota bivalvia dimana menurut Sukarno bahwa suhu yang baik untuk pertumbuhan hewan makrobenthos berkisar antara 25 - 31 ${ }^{\circ} \mathrm{C}$ (Wijayanti, 2007).

b. Salinitas

Salinitas pada lokasi penelitian memiliki rata - rata nilai kisaran antara $28-29$ $\%$. Biota bivalvia dikenal mampu hidup dalam rentang salinitas yang luas. Menurut Gross menyatakan bahwa hewan benthos umumnya dapat mentoleransi salinitas berkisar antara $25-40 \%$. Kisaran salinitas pada lokasi penelitian dengan nilai $28-29$ \% mampu mendukung kehidupan biota bentos bivalvia dengan rentang yang masih ditolerir yakni 25 - $40 \%$ (Wijayanti, 2007)

c. Derajat keasaman $(\mathrm{pH})$

Nilai derajat keasaman $(\mathrm{pH})$ di lokasi penelitian berkisar antara 7,3-7,4. Menurut Barus nilai $\mathrm{pH}$ yang ideal bagi kehidupan organisme laut berkisar antara 6,7-8,2. Ditambahkan Marrison, bivalvia hidup pada batas kisaran $\mathrm{pH}$ 5,8 - 8,3. Dapat disimpulkan bahwa nilai pH pada lokasi penelitian cukup mendukung untuk kehidupan lamun dan bivalvia (Nybakken, 1992).

d. Dissolved Oxygen (DO)

Kisaran oksigen terlarut pada kedua transek penelitian adalah 5,6-6,6. Hasil ini menunjukkan bahwa kadar oksigen terlarut pada lokasi penelitian memiiliki fluktuasi yang cukup. Kisaran oksigen terlarut pada lokasi penelitian mampu menunjangkehidupan biota bivalvia, hal ini sesuai dengan pernyataan Clark bahwa rata - rata kisaran optimum kadar oksigen terlarut bagi moluska bentik yakni berkisar antara 4,1 ppm - 6,6 ppm (Arietika, 2006).

\section{Jenis Lamun}

Bersdasarkan data yang diperoleh dari hasil pengamatan pada dua transek diketahui jenis lamun yang ditemukan di pesisir pantai Ori kecamatan pulau Haruku terdiri dari 4 jenis lamun yang termasuk dalam 2 family yaitu Hydrocharitaceae dan Potamogetonaceae. Keempat spesies lamun tersebut adalah Thalassia hemprichii, dan Enhalus accoroides yang termasuk dalam family Hydrocharitaceae, kemudian 
Cymodocea rotundata dan Halodule pinifolia yang termasuk dalam family Potamogetonaceae.

a. Thalassia hemprichii

Kingdom : Plantae

Divisi : Angiospermae

Kelas : Liliopsida

Ordo : Hydrocharitales

Family : Hydrocharitaceae

Genus : Thalassia

Spesies : Thalassia hemprichii

\begin{tabular}{|l|l|}
\hline Gambar secara umum & Gambar pada lokasi peneliitian \\
\hline Thalassia hemprichii & Gambar 4.1 Thalassia hemprichii \\
\hline
\end{tabular}

Sumber: Data Primer, 2017

b. Enhalus accoroides

Divisi : Magnoliophyta

Kelas : Liliopsida

Bangsa : Hydrocharitales

Suku : Hydrocharitaceae

Marga : Enhalus

Jenis : Enhalus accoroides

\begin{tabular}{|l|l|}
\hline Gambar Secara Umum & Gambar Pada Lokasi Penelitian \\
Enhalus acoroides & Gambar 4.2 Enhalus accoroides \\
\hline
\end{tabular}

Sumber: Data Primer, 2017

BIOLOGI SEL (VOL 7 NO 1 EDISI JAN-JUL 2018 ISSN 2252-858X/E-ISSN 2541-1225) PAGE 86 
c. Cymodocea rotundata

Kingdom : Plantae

Divisi : Antophyta

Kelas : Angiospermae

Ordo : Helobiae

Family : Potamogetonaceae

Genus : Cymodoceae

Spesies : Cymodoceae rotundata

\begin{tabular}{|l|l|}
\hline Gambar Secara Umum & Gambar Pada Lokasi Penelitian \\
\hline Cymodocea rotundata & Gambar 4.3 Cymodoceae rotundata \\
\hline
\end{tabular}

Sumber: Data Primer, 2017

d. Halodule pinifolia

Divisi : Antophyta

Kelas : Angiospermae

Ordo : Helobiae

Family : Potamogetonaceae

Genus : Halodule

Spesies : Halodule pinifolia

\begin{tabular}{|l|l|}
\hline Gambar Secara Umum & Gambar Pada Lokasi Penelitian \\
\hline Halodule pinifolia & Gambar 4.4 Halodule pinifolia \\
\hline
\end{tabular}

Sumber: Data Primer, 2017 
e. Kerapatan Lamun

Berdasarkan hasil penelitian pada transek I dan transek II, keempat jenis lamun yang ditemukan di pesisir pantai Ori kecamatan pulau Haruku dapat dilihat jumlah lamun dan kerapatan jenis lamun yang disajikan pada beberapa tabel dibawah ini:

Tabel 4.2 Jumlah jenis lamun yang ditemukan per transek

\begin{tabular}{|l|l|c|c|}
\hline \multirow{2}{*}{ No } & \multicolumn{1}{|c|}{ Jenis Lamun } & \multicolumn{2}{c|}{ Jumlah Tegakan/Individu } \\
\cline { 3 - 4 } & & Transek I & Transek II \\
\hline 1. & Cymodocea rotundata & 529 & 133 \\
2. & Thalassia hemprichii & 65 & 185 \\
3. & Enhalus accoroides & 4 & 460 \\
4. & Halodule pinifolia & 27 & 67 \\
\hline & \multicolumn{1}{|c|}{ Jumlah } & 625 & 845 \\
\hline
\end{tabular}

Sumber: Data Primer 2017

Dari hasil penelitian jumlah lamun yang ditemukan paling banyak adalah dari jenis Cymodocea rotundata dengan jumlah tegakan/individu 529 pada transek I dan dengan jumlah 133 pada transek II, sedangkan yang paling sedikit ditemukan adalah dari jenis Halodule pinifolia dengan jumlah tegakan/individu 27 pada transek I dan pada transek II dengan jumlah tegakan/individu 67. Jumlah keseluruhan individu pada transek I sebesar 625 dan pada transek II sebesar 845.

Tabel 4.3 Kerapatan Jenis Lamun

\begin{tabular}{|l|l|c|c|c|}
\hline \multirow{2}{*}{ No } & \multicolumn{1}{|c|}{ Jenis Lamun } & \multicolumn{2}{c|}{ Kerapatan individu (ind $/ \mathrm{m}^{2}$ ) } & \multirow{2}{*}{$\begin{array}{c}\text { Total kerapatan } \\
\left.\text { (ind } / \mathrm{m}^{2}\right)\end{array}$} \\
\cline { 3 - 4 } & & Transek I & Transek II & 165,75 \\
1. & Cymodocea rotundata & 132,5 & 33,25 & 62,5 \\
3. & Thalassia hemprichii & 16,25 & 46,25 & 116 \\
4. & Enhalus accoroides & 1 & 115 & 23,5 \\
\hline \multicolumn{2}{|c|}{ Jumlah } & 6,75 & 16,75 & 368 \\
\hline
\end{tabular}

Sumber: Data Primer 2017

Berdasarkan data yang diperoleh, diketahui bahwa jenis lamun Cymodocea rotundata memiliki tingkat kerapatan dengan total kerapatan (ind $/ \mathrm{m}^{2}$ ) terbilang lebih tinggi yaitu sebanyak $165,75 \mathrm{ind} / \mathrm{m}^{2}$. Hal ini dikarenakan lamun jenis ini tahan terhadap kondisi marjinal dan pada tingkat gangguan moderat, serta substrat pantai berupa pasir dan bersedimen rendah batuan membuat Cymodocea rotundata dapat tubuh dengan subur (Thayer et al, 1975). Sedangkan Halodule pinifolia memiliki total kerapatan lebih rendah yaitu $23,5 \mathrm{ind} / \mathrm{m}^{2}$. Lamun biasanya terdapat dalam jumlah yang melimpah dan sering membentuk padang yang lebat dan luas di perairan tropik, menunjukkan spektrum fungsi biologi dan fisik yang lebar, sifat-sifat lingkungan pantai terutama dekat estuaria cocok untuk pertumbuhan dan perkembangan lamun.

Kriteria kerapatan yang tergolong rapat/lebat merupakan kerapatan lamun dengan jumlah tegakan $\geq 100 \mathrm{ind} / \mathrm{m}^{2}$, kerapatan lamun yang tergolong sedang/kurang padat merupakan kerapatan lamun dengan jumlah tegakan $\geq 50-<100 \mathrm{ind} / \mathrm{m}^{2}$, sedangkan kerapatan lamun yang tergolong sangat jarang merupakan kerapatan lamun dengan jumlah tegakan $<50 \mathrm{ind} / \mathrm{m}^{2}$ 9Putra, 2014). Dari hasil perhitungan kerapatan 
lamun denganjumlah total kerapatan sebesar $368 \mathrm{ind} / \mathrm{m}^{2}$ maka dapat di ambil kesimpulan bahwa kerapatan lamun yang terdapat di Pesisir Pantai Ori Kecamatan Pulau Haruku tergolong rapat/lebat.

\section{Spesies Bivalvia}

Berdasarkan hasil pengamatan, diketahui spesies bivalvia yang ditemukan di pesisir pantai Ori Kecamatan Pulau Haruku terdiri dari 4 spesies yaitu Vasticardium flavum, Polymesoda erosa, Pilsbryoconcha exilis, dan Gafrarium pectinatum.

a. Vasticardium flavum

Kingdom : Animalia

Filum : Molusca

Kelas : Bivalvia

Ordo : Veneroida

Family : Cardiidae

Genus : Vasticardium

Spesies : V. flavum

\begin{tabular}{|c|l|}
\hline Gambar Secara Umum & Gambar Pada Lokasi Penelitian \\
\hline & \\
& \\
& Gambar 4.5. Vasticardium flavum \\
\hline
\end{tabular}

Sumber: Data Primer, 2017

b. Polymesoda erosa

Kingdom : Animalia

Filum : Molusca

Kelas : Bivalvia

Ordo : Veroida

Family : Corbiludae

Genus : Polymesoda

Spesies : Polymesoda erosa 


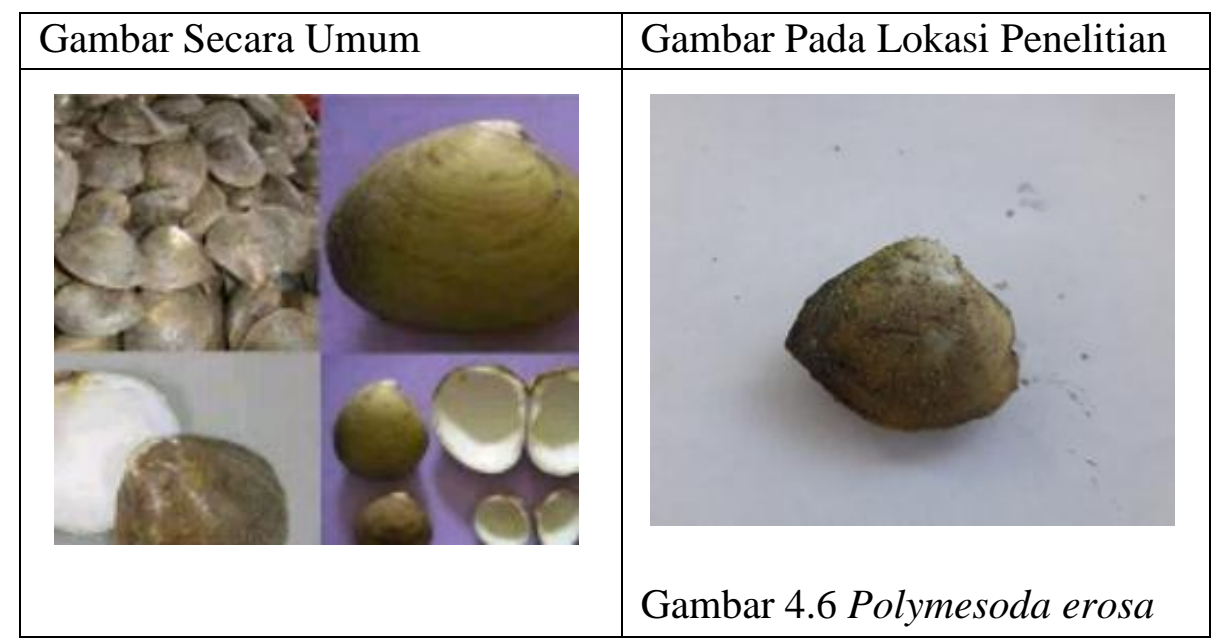

Sumber: Data Primer 2017

c. Pilsbryoconcha exilis

Kingdom : Animalia

Filum : Molusca

Kelas : Bivalvia

Family : Unionidae

Genus : Pilsbryoconcha

Spesies : Pilsbryoconcha exilis

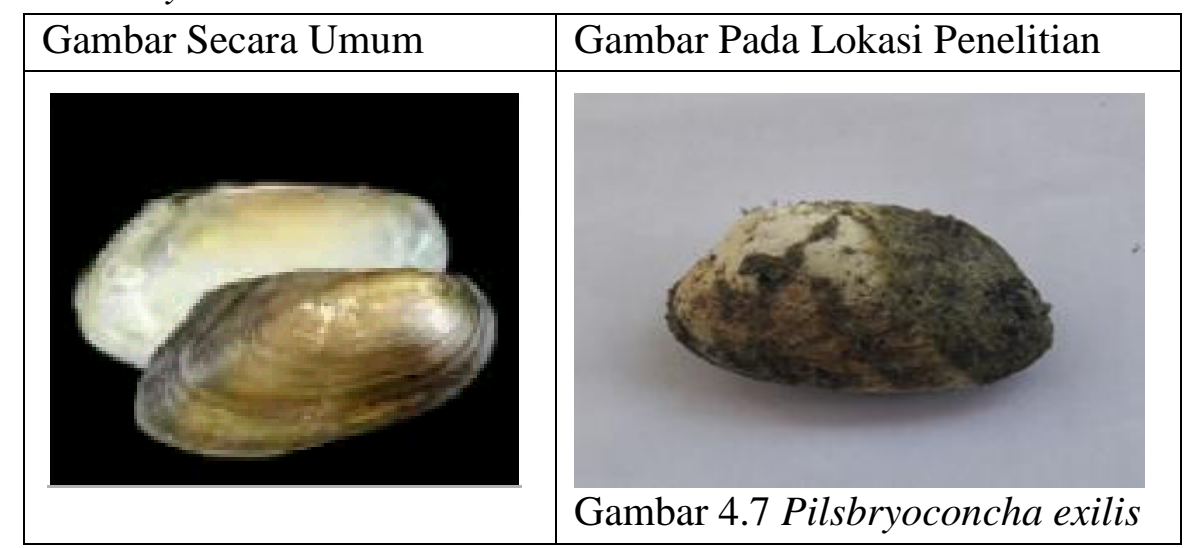

Sumber: Data Primer, 2017

d. Gafrarium pectinatum

Kingdom : Animalia

Filum : Molusca

Kelas : Bivalvia

Ordo : Veneroida

Family : Veneridae

Genus : Gafrarium

Spesies : Gafrarium pectinatum 


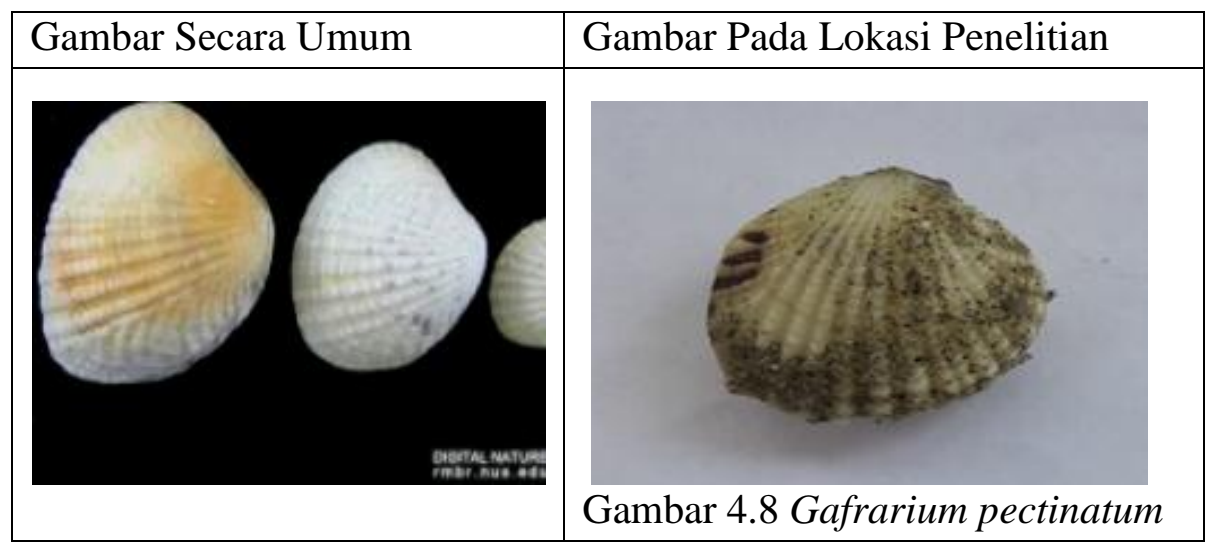

Sumber: Data Primer, 2017

e. Kepadatan Bivalvia

Berdasarkan hasil penelitian dari 4 spesies bivalvia yang ditemukan di pesisir pantai Ori Kecamatan Pulau Haruku tersebut memiliki jumlah satuan yang berbedabeda tiap spesies. Untuk lebih jelasnya dapat dilihat pada tabel berikut ini:

Tabel 4.4 Jumlah spesies bivalvia per transek

\begin{tabular}{|l|l|c|c|c|}
\hline \multirow{2}{*}{ No } & \multicolumn{1}{|c|}{ Spesies } & \multicolumn{2}{|c|}{ Jumlah individu } & Total \\
\cline { 3 - 4 } & & Transek I & Transek II & individu \\
\hline 1. & Vasticardium flavum & 2 & 5 & 7 \\
2. & Polymesoda erosa & 1 & 8 & 9 \\
3. & Pilsbryoconcha exilis & 3 & 2 & 5 \\
4. & Gafrarium pectinatum & 2 & 1 & 3 \\
\hline \multicolumn{2}{|r|}{ Jumlah } & 8 & 16 & 24 \\
\hline
\end{tabular}

Sumber: Data Primer, 2017

Dari hasil penelitian, diduga jumlah spesies bivalvia yang berbeda-beda dipengaruhi oleh faktor-faktor seperti parameter perairan dan aktifitas manusia. Jika dilihat dari tabel 4.3, diketahui bahwa jumlah keseluruhan individu yang ditemukan sebanyak 24 individu. Dengan spesies yang paling banyak ditemukan adalah Polymesoda erosa sebanyak 9 individu. Sedangkan spesies yang paling sedikit jumlah nya adalah Gafrarium pectinatum sebanyak 3 individu.

Keberadaan hewan bentik pada suatu perairan, sangat dipengaruhi oleh berbagai faktor lingkungan perairan. Faktor-faktor tersebut adalah fisika-kimia perairan yang diantaranya adalah suhu, salinitas, arus, $\mathrm{pH}$, kedalaman air, dan substrat dasar, dampak adanya aktifitas manusia disekitar lingkungan perairan juga menyebabkan perubahan kualitas lingkungan perairan tersebut.

Tabel 4.5 Kepadatan spesies Bivalvia

\begin{tabular}{|c|c|c|c|c|}
\hline \multirow{2}{*}{ No } & \multirow{2}{*}{ Spesies } & \multicolumn{2}{|c|}{ Kepadatan individu (ind $/ \mathrm{m}^{2}$ ) } & \multirow{2}{*}{ Total kepadatan (ind/m²) } \\
\hline & & Transek I & Transek II & \\
\hline 1. & Vasticardium flavum & 0,5 & 1,25 & 1,75 \\
\hline 2. & Polymesoda erosa & 0,25 & 2 & 2,25 \\
\hline 3. & Pilsbryoconcha exilis & 0,75 & 0,5 & 1,25 \\
\hline \multirow[t]{2}{*}{4.} & Gafrarium pectinatum & 0,5 & 0,25 & 0,75 \\
\hline & \multicolumn{3}{|c|}{ Jumlah } & 6 \\
\hline
\end{tabular}

Sumber: Data Primer, 2017

BIOLOGI SEL (YOL 7 NO 1 EDISI JAN-JUL 2018 ISSN 2252-858X/E-ISSN 2541-1225) PAGE 91 
Setelah mengetahui jumlah per individu setiap spesies lamun, selanjutnya dilakukan perhitungan untuk megetahui tingkat kepadatan bivalvia yang terdapat di Pesisir Pantai Ori Kecamatan Pulau Hruku. Berdasarkan data yang diperoleh, diketahui bahwa kepadatan bivalvia yang tertinggi dijumpai pada spesies Polymesoda erosa dengan total kepadatan $2,25 \mathrm{ind} / \mathrm{m}^{2}$ sedangkan tingkat kelimpahan terendah dijumpai pada spesies Gafrarium pectinatum dengan total kepadatan $0,75 \mathrm{ind} / \mathrm{m}^{2}$.

\section{Hubungan Kerapatan Lamun Dengan Kepadatan Bivalvia}

Berdasarkan hasil pengamatan, dibawah ini disajikan beberapa tabel sebaran data jumlah lamun dan jumlah bivalvia yang di teliti pada masing-masing transek yakni transek I dan transek II dengan jumlah kuadran pada transek I adalah 4 kuadran dan transek II adalah 4 kuadran, dengan sebaran data sebagai berikut:

Tabel 4.6. Jumlah Tegakan Jenis Lamun dan Jumlah Individu Bivalvia Tiap Kuadran Pada Transek I

\begin{tabular}{|c|c|c|c|c|c|}
\hline \multirow[b]{2}{*}{ No } & \multicolumn{5}{|c|}{ Transek I } \\
\hline & $\mathrm{K}$ & Jenis Lamun & $\begin{array}{c}\text { Jumlah } \\
\text { Tegakan }\end{array}$ & Jenis Bivalvia & $\begin{array}{c}\text { Jumlah } \\
\text { Individu }\end{array}$ \\
\hline 1. & I & $\begin{array}{l}\text { Cymodocea rotundata } \\
\text { Thalassia hemprichii } \\
\text { Enhalus accoroides } \\
\text { Halodule pinifolia }\end{array}$ & $\begin{array}{c}196 \\
14 \\
- \\
- \\
\end{array}$ & $\begin{array}{l}\text { Vasticardium flavum } \\
\text { Polymesoda erosa } \\
\text { Pilsbryoconscha exilis } \\
\text { Gafrarium pectinatum }\end{array}$ & $\begin{array}{l}1 \\
- \\
- \\
1\end{array}$ \\
\hline 2. & II & $\begin{array}{l}\text { Cymodocea rotundata } \\
\text { Thalassia hemprichii } \\
\text { Enhalus accoroides } \\
\text { Halodule pinifolia }\end{array}$ & $\begin{array}{c}106 \\
19 \\
4 \\
13\end{array}$ & $\begin{array}{l}\text { Vasticardium flavum } \\
\text { Polymesoda erosa } \\
\text { Pilsbryoconcha exilis } \\
\text { Gafrarium pectinatum }\end{array}$ & $\begin{array}{l}- \\
1 \\
2 \\
-\end{array}$ \\
\hline 3. & III & $\begin{array}{l}\text { Cymodocea rotundata } \\
\text { Thalassia hemprichii } \\
\text { Enhalus accoroides } \\
\text { Halodule pinifolia }\end{array}$ & $\begin{array}{c}103 \\
17 \\
- \\
14\end{array}$ & $\begin{array}{l}\text { Vasticardium flavum } \\
\text { Polymesoda erosa } \\
\text { Pilsbryoconcha exilis } \\
\text { Gafrarium pectinatum }\end{array}$ & $\begin{array}{l}- \\
- \\
1 \\
-\end{array}$ \\
\hline 4. & IV & $\begin{array}{l}\text { Cymodocea rotundata } \\
\text { Thalassia hemprichii } \\
\text { Enhalus accoroides } \\
\text { Halodule pinifolia }\end{array}$ & $\begin{array}{c}124 \\
15 \\
- \\
-\end{array}$ & $\begin{array}{l}\text { Vasticardium flavum } \\
\text { Polymesoda erosa } \\
\text { Pilsbryoconcha exilis } \\
\text { Gafrarium pectinatum }\end{array}$ & $\begin{array}{l}1 \\
- \\
- \\
1\end{array}$ \\
\hline
\end{tabular}

Sumber: Data Primer, 2017

Tabel 4.7. Jumlah Tegakan Lamun dan Jumlah Individu Bivalvia Tiap Kuadran Pada Transek II

\begin{tabular}{|c|c|c|c|c|c|}
\hline \multirow[b]{2}{*}{ No } & \multicolumn{5}{|c|}{ Transek II } \\
\hline & $\mathrm{K}$ & Jenis Lamun & $\begin{array}{c}\text { Jumlah } \\
\text { Tegakan }\end{array}$ & Jenis Bivalvia & $\begin{array}{c}\text { Jumlah } \\
\text { Individu }\end{array}$ \\
\hline 1. & I & $\begin{array}{l}\text { Cymodocea rotundata } \\
\text { Thalassia hemprichii } \\
\text { Enhalus accoroides } \\
\text { Halodule pinifolia }\end{array}$ & $\begin{array}{c}94 \\
28 \\
- \\
67\end{array}$ & $\begin{array}{l}\text { Vasticardium flavum } \\
\text { Polymesoda erosa } \\
\text { Pilsbryoconcha exilis } \\
\text { Gafrarium pectinatum }\end{array}$ & $\begin{array}{l}2 \\
1 \\
- \\
1\end{array}$ \\
\hline 2. & II & $\begin{array}{l}\text { Cymodocea rotundata } \\
\text { Thalassia hemprichii } \\
\text { Enhalus accoroides } \\
\text { Halodule pinifolia }\end{array}$ & $\begin{array}{c}- \\
38 \\
175 \\
-\end{array}$ & $\begin{array}{l}\text { Vasticardium flavum } \\
\text { Polymesoda erosa } \\
\text { Pilsbryoconcha exilis } \\
\text { Gafrarium pectinatum }\end{array}$ & $\begin{array}{l}- \\
3 \\
1 \\
-\end{array}$ \\
\hline 3. & III & $\begin{array}{l}\text { Cymodocea rotundata } \\
\text { Thalassia hemprichii } \\
\text { Enhalus accoroides } \\
\text { Halodule pinifolia }\end{array}$ & $\begin{array}{c}23 \\
29 \\
125 \\
-\end{array}$ & $\begin{array}{l}\text { Vasticardium flavum } \\
\text { Polymesoda erosa } \\
\text { Pilsbryoconcha exilis } \\
\text { Gafrarium pectinatum }\end{array}$ & $\begin{array}{l}1 \\
1 \\
1 \\
-\end{array}$ \\
\hline 4. & IV & Cymodocea rotundata & 16 & Vasticardium flavum & 2 \\
\hline
\end{tabular}

BIOLOGI SEL (VOL 7 NO 1 EDISI JAN-JUL 2018 ISSN 2252-858X/E-ISSN 2541-1225) PAGE 92 


\begin{tabular}{|c|c|c|c|c|c|}
\hline & & $\begin{array}{l}\text { Thalassia hemprichii } \\
\text { Enhalus accoroides } \\
\text { Halodule pinifolia }\end{array}$ & $\begin{array}{c}90 \\
160 \\
- \\
\end{array}$ & $\begin{array}{l}\text { Polymesoda erosa } \\
\text { Pilsbryoconcha exilis } \\
\text { Gafrarium pectinatum }\end{array}$ & - \\
\hline
\end{tabular}

Sumber: Data Primer 2017

Pada penelitian ini, untuk mengetahui hubungan kerapatan lamun terhadap kepadatan bivalvia yang dilakukan dengan menggunakan uji korelasi. Berikut hasil perhitungn uji korelasi pada tabel 4.6 dibawah ini:

Tabel 4.8 korelasi kerapatan lamun dengan kepadatan bivalvia

\begin{tabular}{|ll|r|r|}
\hline & \multicolumn{1}{c|}{$\begin{array}{c}\text { Kerapatan } \\
\text { Lamun }\end{array}$} & $\begin{array}{c}\text { kepadatan } \\
\text { Bivalvia }\end{array}$ \\
\hline Kerapatan Lamun & Pearson Correlation & 1 & .347 \\
& Sig. (2-tailed) & 4 & .653 \\
kepadatan Bivalvia & $\mathrm{N}$ & .347 & 4 \\
& Pearson Correlation & .653 & 1 \\
& Sig. (2-tailed) & 4 & 4 \\
\hline
\end{tabular}

Sumber: analisis data penelitian tahun 2017

Berdasarkan hasil perhitungan uji korelasi pada tabel 4.6 diketahui nilai korelasi sebesar 0,347 dengan taraf signifikansi sebesar 0,653. Menurut kategori Korelasi Pearson jika $\mathrm{r}=0$, maka tidak ada korelasi, $\mathrm{r}=0-0,5$ maka hubungan antara kedua variabel lemah, $r=0,5-0,8$ maka hubungan antara kedua variabel kategori sedang, $r=$ 0,8 -1 maka hubungan kedua variabel sangat kuat atau erat, $r=1$ maka hubungan antara kedua variabel sempurna, jika $r=(-1)$ maka hubungan sangat kuat dan bersifat tidak searah dan jika $r=(+1)$ maka hubungannya sangat kuat bersifat searah. Dari data pada tabel 4.6 dapat diambil kesimpulan bahwa nilai uji korelasi di Pesisir Pantai Ori Kecamatan Pulau Haruku masuk kedalam kategori $r=0-0,5$, maka hubungan antara kerapatan lamu dan kepadatan bivalvia dikatakan lemah. Hal ini bearti data yang dikumpulkan tidak berhasil membuktikan hubungan antara variabel $\mathrm{x}$ dan variabel $\mathrm{y}$, bukan bearti kedua variabel tersebut tidak berhubungan. Dari hasil uji korelasi juga dapat disimpulkan bahwa hubungan dari kerapatan lamun dan kepadatan bivalvia di Pesisir Pantai Ori kecamatan Pulau Haruku sangat lemah.

Kemudian berdasarkan taraf signifikansi jika sig diatas 0,05 maka $\mathrm{H}_{0}$ diterima dan $\mathrm{H}_{1}$ di tolak. Dan jika sig dibawah 0,05 maka $\mathrm{H}_{0}$ ditolak dan $\mathrm{H}_{1}$ diterima. Pada tabel 4.8 untuk taraf signifikansi sebesar 0,653 lebih besar dari 0,05 maka diputuskan bahwa $\mathrm{H}_{0}$ diterima dan $\mathrm{H}_{1}$ ditolak. Hal ini berarti bahwa tidak ada hubungan kerapatan lamun dengan kepadatan bivalvia di pesisir pantai Ori kecamatan pulau haruku.

Jenis lamun yang ditemukan di pesisir pantai Ori Kecamatan Pulau Haruku terdiri dari 4 jenis dari 2 family. Jenis lamun yang ditemukan yaitu Thalassia hemprichii, dan Enhalus accoroides yang termasuk dalam family Hydrocharitaceae, kemudian Cymodocea rotundata dan Halodule pinifolia yang termasuk dalam family Potamogetonaceae. Zonasi padang lamun pada pesisir pantai Ori Kecamatan Pulau 
Haru pada transek I didominasi dengan lamun jenis Cymodocea rotundata, kemudian pada transek II di dominasi oleh lamun jenis Enhalus accoroides. Hasil yang diperoleh dari kedua transek menunjukkan bahwa lokasi penelitian memiliki jumlah dan jenis lamun yang berbeda. Dari kedua transek didapatkan hasil bahwa jenis Cymodocea rotundata ditemukan paling banyak dibandingkan jenis lamun lainnya dengan jumlah keseluruhan dari transek I dan transek II sebanyak 662 tegakan. Sedangkan jenis yang paling sedikit ditemukan yaitu Halodule pinifolia sebanyak 94 tegakan.Kedua transek penelitian memiliki kerapatan lamun yang berbeda-beda. Dari kedua transek tersebut didapatkan jumlah total kerapatan lamun sebesar $368 \mathrm{ind} / \mathrm{m}^{2}$ dengan demikian dapat diketahui bahwa kondisi padang lamun di pesisir pantai Ori Kecamatan Pulau Haruku termasuk ke dalam kategori padat atau lebat.

Jumlah spesies bivalvia yang ditemukan pada padang lamun untuk transek I sebanyak 8 individu dan transek II sebanyak 16 individu, dengan jumlah total sebanyak 24 individu.Spesies bivalvia yang ditemukan sebanyak 4 spesies antara lain Vasticardium flavum, Polymesoda erosa, Pilsbryoconcha exilis, dan Gafrarium pectinatum. Nilai kepadatan bivalvia tertinggi dijumpai pada spesies Polymesoda erosa dengan kepadatan $2,25 \mathrm{ind} / \mathrm{m}^{2}$, sedangkan tingkat kepadatan terendah dijumpai pada spesies Gafrarium pectinatum dengan kepadatan $0,75 \mathrm{ind} / \mathrm{m}^{2}$. Bivalvia yang ditemukan pada tansek I lebih sedikit dibandingkan pada transek II. Hal ini dikarenakan tipe substrat pada transek I lebih banyak bebatuan/ berbatu dengan salinitas yang lebih rendah dibandingkan transek II. Sebab transek I merupakan pesisir pantai yang dekat dengan pemukiman warga sehingga cenderung bercampur dengan air tawar, hal ini yang merupakan salah satu penyebab sedikitnya bivalvia yang ditemukan. Berbeda halnya dengan transek II dengan substrat berpasir dan salinitas lebih tinggi dibandingkan stasiun I. sehingga bivalvia yang ditemukan juga lebih banyak jumlahnya.

Kepadatan bivalvia di pesisir pantai Ori Kecamatan Pulau Haruku dapat dikatakan kurang padat sebab tidak banyak jumlah individu yang ditemukan. Hal ini dikarenakan keberadaan hewan bentik pada suatu perairan, sangat dipengaruhi oleh berbagai faktor lingkungan perairan, selain faktor -faktor seperti suhu, salinitas, $\mathrm{pH}$, DO, kedalaman air, substrat dasar, adapula dampak adanya aktifitas manusia disekitar lingkungan perairan seperti pembuangan limbah industri rumah tangga yang menyebabkan perubahan kualitas lingkungan perairan tersebut.

Sebaran suhu di pesisir pantai Ori Kecamatan Pulau Haruku pada transek I dan transek II berkisar antara $29-30^{\circ} \mathrm{C}$. Menurut Raymont, suhu optimum untuk pertumbuhan optimal organisme pada perairan tropis berkisar antara $25-32^{\circ} \mathrm{C}$, sehingga suhu di kedua perairan ini masih optimal bagi pertumbuhan Bivalvia (raymont, 1963). Secara umum $\mathrm{pH}$ terendah di sekitar dan semakin besar ketika mendekati daerah laut lepas menunjukkan kisaran $\mathrm{pH}$ yang masih menunjang kehidupan Bivalvia. Model

BIOLOGI SEL (YOL 7 NO 1 EDISI JAN-JUL 2018 ISSN 2252-858X/E-ISSN 2541-1225) PAGE 94 
hubungan antara kerapatan jenis lamun terhadap kepadatan Bivalvia menunjukkan hubungan yang sangat lemah.

\section{KESIMPULAN}

1. Jenis lamun yang ditemukan terdiri dari 4 jenis lamunyaitu Thalassia hemprichii, Enhalus accoroides, Cymodocea rotundata, Halodule pinifolia. Kerapatan tiap-tiap jenis lamun berbeda-beda, berdasarkan jenis lamun yang ditemukan, yang banyak dijumpai adalah Cymodocea rotundata dengan tingkat kerapatan tertinggi yaitu $165,75 \mathrm{ind} / \mathrm{m}^{2}$, sedangkan jenis lamun yang paling sedikit ditemukan adalah Halodule pinifolia dengan tingkat kerapatan paling rendah yaitu $23,5 \mathrm{ind} / \mathrm{m}^{2}$. Jumlah total kerapatan lamun pada kedua transek sebesar $368 \mathrm{ind} / \mathrm{m}^{2}$. Kerapatan lamun di Pesisir Pantai Ori Kecamatan Pulau Haruku masuk dalam kategori rapat/lebat.

2. Spesies bivalvia yang ditemukan terdiri dari 4 jenis yaitu yaitu Vasticardium flavum, Polymesoda erosa, Pilsbryoconcha exilis, dan Gafrarium pectinatum. Kepadatan pada tiap-tiap spesies berbeda-beda, dari jenis bivalvia yang ditemukan yang dominan dijumpai adalah spesies Polymesoda erosa sebanyak 9 individu dengan tingkat kepadatan 2,25 ind $/ \mathrm{m}^{2}$, sedangkan jenis bivalvia yang paling sedikit dijumpai adalah spesies Gafrarium pectinatum sebanyak 3 individu dengan tingkat kepadatan $0,75 \mathrm{ind} / \mathrm{m}^{2}$. Jumlah total kepadatan bivalvia sebesar $6 \mathrm{ind} / \mathrm{m}^{2}$.

3. Hubungan kerapatan lamun dan kepadatan bivalvia di Pesisir Pantai Ori kecamatan Pulau Haruku tergolong sangat lemah, hal ini berdasarkan hasil nilai korelasi yang diperoleh yaitu 0,347 dan diperkuat dengan taraf signifikansi sebesar 0,653 lebih besar dari 0,05. Hal ini berarti bahwa tidak ada hubungan kerapatan lamun dengan kepadatan bivalvia di pesisir pantai Ori kecamatan pulau haruku.

\section{DAFTAR PUSTAKA}

Akhrianti, Irma. 2014. Distribusi Spasial Dan Preferensi Habitat Bivalvia Di Pesisir Kecamatan Simpang Pesak Kabupaten Belitung Timur, Skripsi Program Studi Ilmu Kelautan Sekolah Pasca Sarjana Institut Pertanian Bogor.

Sutriyah. 2015. Inventarisasi Jenis-Jenis Bivalvia Di Zona Interdal Perairan Teluk Tomini Kecamatan Batuda Pantai Kabupaten Gorontalo Provinsi Gorontalo, (Jurnal: Jurusan Manajemen Sumber Daya Perairan, Fakultas Perikanan Dan Kelautan, Universitas Negeri Gorontalo.

Dahuri, R.J.Rais, S.P. Ginting dan M.J. Sitepu. Zool. 2011. Pengelolaan sumber daya wilayah Pesisir dan Lautan Secara Terpadu.Firsted. Jakarta: Pradnya Paramitha

Hermala. Zulfikar, Andi. T. Said Raza'i. 2015. Hubungan Kerapatan Lamu Dengan Kelimpahan Bivalvia Di Pesisir Pantai Dolpin Desa Teluk Bakau Kabupaten Bintan. (Jurnal: Program Studi Manajemen Sumber Daya Perairan FIKP UMRAH 
K, Romimohtarto dan S, Juwana. 2009. Biologi Laut. Ilmu Pengetahuan Tentang Biologi Laut. Penerbit Djambatan: Jakarta

Nontji, A.2002. Laut Nusantara. Penerbit Djambatan: Jakarta

C.den. Hartog 1970. Seagrass Of The World. North Holland Publ.Co. Kikuchi dan J.M. Peres: Amsterdam.

Senawiratama. http//senawiratama.files.wrdpress.cm/2010/08/bivalvia.pdf. Diakses Tanggal 20 Februari 2017.

Hikmat, Mahi. 2011. Metode Penelitian Dalam Perspektif Ilmu Dan Sastra. Graha Ilmu: Yogyakarta

Nazir, Moh. 2009. Metode Penelitian. Penerbit Ghalia Indonesia: Bogor 